\title{
Non-immune hydrops fetalis: A retrospective analysis of 151 autopsies performed at a single center
}

\author{
Gözdem Kaykı1 ${ }^{1}$, Şafak Güçer ${ }^{2}$, Zuhal Akçören², Diclehan Orhan², Beril Talim², \\ Murat Yurdakök ${ }^{3}$, Șule Yiğit ${ }^{3}$, Osman Koray Boduroğlu${ }^{4}$, Gülen Eda Utine ${ }^{4}$, Gökçen \\ Örgül ${ }^{5}$, M. Sinan Beksaç5 \\ ${ }^{2}$ Division of Pediatric Pathology, ${ }^{3}$ Neonatology, ${ }^{4}$ Genetics and Departments of ${ }^{1}$ Pediatrics, and ${ }^{5}$ Division of Perinatology, \\ Obstetrics and Gynecology, Hacettepe University Faculty of Medicine, Ankara, Turkey. E-mail: sgucer@hacettepe.edu.tr \\ Received: 1st December 2017, Revised: 7th January 2018, Accepted: 07th January 2018
}

SUMMARY: Kaykı G, Güçer Ş, Akçören Z, Orhan D, Talim B, Yurdakök M, Yiğit Ş, Boduroğlu OK, Utine GE, Örgül G, Beksac MS. Non-immune hydrops fetalis: A retrospective analysis of 151 autopsies performed at a single center. Turk J Pediatr 2018; 60: 471-477.

We retrospectively evaluated autopsies performed on 151 non-immune hydrops fetalis (NIHF) cases to determine the etiology and pathological findings. Further, cases identified between 1980 and 2004 were compared with those identified between 2005 and 2015 to investigate the improvement of diagnostic performance of our institution. The mean gestational age during the fetal autopsy was 25 weeks. There were 30 live-born infants in the study group. The etiology of NIHF could be determined in 91 cases $(60.3 \%)$, while it remained undefined in remaining 60 cases. The most commonly associated pathological conditions were cardiovascular malformations $(11.3 \%)$, followed by chromosomal abnormalities $(9.3 \%)$. Prior to $20^{\text {th }}$ gestation week, genetic anomalies and cystic hygromas were the most common etiological factors, and after 30 weeks of gestation, cardiac abnormalities were found to be the most common causes. With time, the rate of undefined cases decreased from $48.4 \%$ to $33.75 \%$. NIHF is a complex medical condition necessitating a multidisciplinary management approach. Progress in molecular genetics and imaging techniques is expected to improve diagnostic performance for rapid and better identification.

Key words: congenital malformations, etiology, fetal autopsy, perinatal autopsy, nonimmune hydrops fetalis.

Hydrops fetalis (HF) is defined as excessive accumulation of fluid in two or more fetal compartments including the skin, pleura, pericardium, placenta, and/or peritoneum. ${ }^{1,2}$ $\mathrm{HF}$ is associated with a wide spectrum of pathological conditions and is clinically classified into immune and non-immune HF. . $^{3,4}$ Recently, it has been shown that approximately $90 \%$ of HF cases can be categorized into the non-immune group, especially after anti-D prophylaxis has started being routinely administered to rhesusnegative pregnant women, which has led to prevention of immune HF. ${ }^{5}$

The incidence of non-immune hydrops fetalis (NIHF) is 1 in 2000-3500 live births. 6,7 NIHF is caused by a heterogeneous group of conditions that present as various signs and symptoms, such as liver failure, heart failure, and reduced lymph flow. ${ }^{3,8}$ In most cases, prenatal ultrasonography can detect the features associated particularly with this condition. ${ }^{9,10}$ Identifying NIHF etiology is important, especially in cases that require intrauterine interventions. ${ }^{11,12}$ Fetal autopsy is critical in definitively diagnosing and/ or confirming the etiopathogenesis of NIHF cases. ${ }^{8,13}$

We aimed to demonstrate the importance of performing a fetal autopsy for the evaluation of NIHF cases. Additionally, we compared the data of the fetuses identified with NIHF between 1980-2004 and between 2005-2015 to indicate the diagnostic progress that has been achieved in this field. 


\section{Material and Methods}

We studied fetal autopsy results of $179 \mathrm{HF}$ cases and found that $84.4 \%(151 / 179)$ of them were NIHF cases. Hacettepe University Hospital Registry was used to obtain the necessary data (fetal autopsy results, laboratory test results, and demographic features, among other information) during two periods (1980-2004 and 2005-2015). We found 62 and 89 NIHF cases during the 1980-2004 and 2005-2015 periods, respectively.

Gestational/birth and demographic data include maternal age, gestational age at birth/ termination, birth weight, gender, examination of placenta, results of chromosomal analysis, serological test results, survival time, associated

Table I. Live Born Cases with Non-Immune Hydrops Fetalis.

\begin{tabular}{|c|c|c|c|c|c|}
\hline $\begin{array}{l}\text { Case } \\
\text { number }\end{array}$ & $\begin{array}{l}\text { Gestational age } \\
\text { at birth } \\
\text { (weeks) }\end{array}$ & $\begin{array}{l}\text { Weight } \\
(\mathrm{g})\end{array}$ & Gender & $\begin{array}{c}\text { Survival } \\
\text { time }\end{array}$ & Etiology \\
\hline 1 & 27 & 2065 & $\mathrm{M}$ & $10 \mathrm{~min}$ & Thoracic \\
\hline 2 & 33 & 1700 & $\mathrm{~F}$ & 1 hour & Idiopathic \\
\hline 3 & 34 & 960 & M & 1 hour & Idiopathic \\
\hline 4 & 38 & 3000 & M & 4 hours & Renal (polycystic kidney) \\
\hline 5 & 35 & 3000 & $\mathrm{~F}$ & 1 day & Idiopathic \\
\hline 6 & 35 & 2050 & M & 1 day & Idiopathic \\
\hline 7 & 32 & 2170 & $\mathrm{~F}$ & 1 day & Idiopathic \\
\hline 8 & 39 & 3750 & M & 1 day & Idiopathic \\
\hline 9 & 36 & 2585 & $\mathrm{~F}$ & 1 day & Idiopathic \\
\hline 10 & 33 & 2040 & $\mathrm{~F}$ & 1 day & Idiopathic \\
\hline 11 & 35 & 1700 & M & 1 day & Idiopathic \\
\hline 12 & 32 & 1398 & M & 1 day & Cardiac \\
\hline 13 & 37 & 3000 & M & 1 day & $\begin{array}{l}\text { Inborn error of metabolism } \\
\text { (Zellweger syndrome) }\end{array}$ \\
\hline 14 & 36 & 2585 & M & 1 day & $\begin{array}{c}\text { Renal (congenital nephrotic } \\
\text { syndrome) }\end{array}$ \\
\hline 15 & 30 & 2050 & M & 1 day & Renal \\
\hline 16 & 26 & 825 & $\mathrm{~F}$ & 1 day & Chorioangioma \\
\hline 17 & 33 & 2440 & M & 2 days & Idiopathic \\
\hline 18 & 35 & 2240 & $\mathrm{~F}$ & 2 days & Cardiac \\
\hline 19 & 38 & 3250 & $\mathrm{~F}$ & 2 days & Anemia \\
\hline 20 & 34 & 3250 & $\mathrm{~F}$ & 2 days & Anemia \\
\hline 21 & 31 & 1600 & $\mathrm{~F}$ & 2 days & Chromosomal (Down syndrome) \\
\hline 22 & 31 & 2180 & M & 3 days & Anemia \\
\hline 23 & 34 & 3620 & M & 3 days & Idiopathic \\
\hline 24 & 35 & 4180 & M & 4 days & Cardiac \\
\hline 25 & 37 & - & M & 4 days & Cardiac \\
\hline 26 & 33 & 2950 & $\mathrm{~F}$ & 6 days & Cardiac \\
\hline 27 & 31 & 1925 & M & 6 days & Anemia \\
\hline 28 & 36 & 2850 & M & 11 days & Idiopathic \\
\hline 29 & 34 & 2600 & M & 17 days & Cardiac \\
\hline 30 & 34 & 3070 & $\mathrm{~F}$ & 53 days & $\begin{array}{c}\text { Inborn error of metabolism (Niemann } \\
\text { Pick type C) }\end{array}$ \\
\hline
\end{tabular}

F: Female, M: Male, min: minute 
Table II. Etiology of Non-Immune Hydrops Fetalis (NIHF) with Comparison of Findings Between Two Periods (1980-2004 and 2005-2015).

\begin{tabular}{lcccl}
\hline & $\begin{array}{c}1980-2004 \\
(\mathrm{n}=62) \\
\mathrm{n}\left(\%^{*}\right)\end{array}$ & $\begin{array}{c}2005-2015 \\
(\mathrm{n}=89) \\
\mathrm{n}\left(\%^{*}\right)\end{array}$ & $\begin{array}{c}\mathrm{P} \text { value } \\
\text { Etiology }\end{array}$ & $\begin{array}{c}1980-2015 \\
(\mathrm{n}=151) \\
\mathrm{n}(\% *)\end{array}$ \\
Cardiac & $4(6.5)$ & $13(14.6)$ & 0.119 & $17(11.3 \%)$ \\
Chromosomal & $1(1.6)$ & $13(14.6)$ & 0.007 & $14(9.3 \%)$ \\
Cystic hygroma & $2(3.2)$ & $9(10.1)$ & 0.201 & $11(7.3 \%)$ \\
Urinary tract disorders & $6(9.6)$ & $4(4.5)$ & 0.488 & $10(6.6 \%)$ \\
Twin-twin transfusion & $3(4.8)$ & $4(4.5)$ & 1.000 & $7(4.6 \%)$ \\
Thoracic & $5(8.1)$ & $1(1.1)$ & 0.043 & $6(4 \%)$ \\
Infectious & $3(4.8)$ & $2(2.2)$ & 0.402 & $5(3.3 \%)$ \\
Skeletal system & $1(1.6)$ & $4(4.5)$ & 0.649 & $5(3.3 \%)$ \\
Syndromic & $3(4.8)$ & $2(2.2)$ & 0.402 & $5(3.3)$ \\
Hematological & $3(4.8)$ & $2(2.2)$ & 0.229 & $5(3.3 \%)$ \\
Inborn errors of metabolism & 0 & $3(3.4)$ & 0.269 & $3(2 \%)$ \\
Idiopathic & $30(48.4)$ & $30(33.7)$ & 0.070 & $60(39.7 \%)$ \\
Other** & $1(1.6)$ & $2(2.2)$ & 1.000 & $3(2 \%)$ \\
\hline
\end{tabular}

*Percentage of column

${ }^{* *}$ Central nervous system anomalies, chorioangioma, maternal Sjögren syndrome

abnormalities, maternal risk factors, and fetal autopsy results.

This study was approved by the ethical committee of Hacettepe University with number of GO-918. All parents were informed about the autopsy and written consent was obtained.

All statistical analyses were performed using SPSS version 22.0 software (SPSS Inc., Chicago, IL, USA). Descriptive statistics were presented as frequencies and percentages. Categorical variables were analyzed using the Pearson chi-square test and the Fisher exact test. A $\mathrm{P}$ value of $<0.05$ was considered statistically significant.

\section{Results}

We retrospectively evaluated autopsy results $(n=4377)$ of the fetuses operated on between 1980 and 2015. We found 179 cases with HF and 151 (84.4\%) among them were NIHF cases.

Mean gestational age at the time of autopsy was 25 weeks (range 11-39 gestational weeks). Mean maternal age was 26.9 years (range 1744). There were 30 live-born infants (30/151, $19.8 \%$ ) in the study group (Table I). Survival time varied between 10 minutes and 53 days. Mean birth weight was $1149 \mathrm{~g}$ (range 3.7-4180 g) in all NIHF cases. We found that $47 \%$ of the cases were female infants.

Etiology of NIHF could be identified in 91 cases $(60.3 \%)$, while it remained undetermined in the remaining 60 cases, which were defined as idiopathic (Table II). The most common etiological factor identified was cardiovascular diseases $(11.3 \%)$, followed by chromosomal disorders $(9.3 \%)$, cystic hygroma $(7.3 \%)$, renal abnormalities (6.6\%), and twin-to-twin transfusion syndrome (4.6\%).

We divided our study cases into two groups: cases between 1980-2005 and those identified between 2005-2015. A comparison between the groups (Table II) showed that the number of cases classified as demonstrating undefined etiology decreased from $48.4 \%$ to $33.7 \%(p=0.007)$. Although urinary system disorders were the most common cause identified in the period between 1980 and 2005 , cardiovascular diseases (14.6\%) and chromosomal abnormalities (14.6\%) were identified as the two most common etiological factors in the period between 2006 and 2015. Fetal karyotyping was performed in 58 cases $(38.4 \%)$. Tables III and IV show NIHF-associated cardiovascular disorders and 
Table III. Cardiovascular Causes.

\begin{tabular}{lcc}
\hline & Number of cases & Percentage (\%) \\
\hline Atrial septal defect & 4 & 23.5 \\
Cardiomegaly & 2 & 12.7 \\
Atrioventricular septal defect & 1 & 5.8 \\
Ebstein's anomaly & 1 & 5.8 \\
Single ventricle defect & 1 & 5.8 \\
Single atrium & 1 & 5.8 \\
Cor biloculare & 1 & 5.8 \\
Endocardial fibroelastosis & 1 & 5.8 \\
Hypoplasia of the aorta & 1 & 5.8 \\
Tricuspid stenosis & 1 & 5.8 \\
Double outlet right ventricle & 1 & 5.8 \\
Pulmonary stenosis & 1 & 5.8 \\
Noncompaction cardiomyopathy & 1 & 5.8 \\
\hline Total & 17 & 100 \\
\hline
\end{tabular}

chromosomal abnormalities, respectively.

Table V shows "gestational-age related" distribution of chromosomal and structural abnormalities in addition to other etiological findings. We found that in 48 cases gestational age was $\leq 20$ weeks, in 53 cases gestational age was 20-30 weeks, and in 50 cases gestational age was $\geq 30$ weeks. Genetic abnormalities were noted to be more common before 20 weeks $(p=0.001)$. Chromosomal abnormalities and cystic hygroma were found to be more frequent before the $20^{\text {th }}$ gestational week, while cardiac problems were more frequent during the later stages of pregnancy (Table V), especially after the $30^{\text {th }}$ gestational week $(p=0.007)$.

Placental examination was available in 41 of 89 cases in the last ten years. Hydropic changes in the placenta were present in $85 \%$ of them, and dystrophic calcifications were present in $31 \%$. Three placenta examinations showed the findings that strengthened the diagnosis of twin to twin transfusions. Also, single umbilical artery in two placenta examinations and a giant chorioangioma in one were detected.

\section{Discussion}

NIHF is caused by several etiological factors, which could be related to maternal, fetal and/or placental causes. Impaired vascular permeability, and alterations in osmotic/oncotic pressure, lymphatic drainage, and venous pressure are described as the biological rationales to explain the occurrence of NIHF. 2,14 Clinically, a prenatal ultrasonographic examination helps to detect NIHF. The most common abnormalities detected through ultrasonography are fetal ascites, pleural effusion, pericardial fluid accumulation, skin edema, placentomegaly, and polyhydramnios. ${ }^{13,15}$

In cases showing a high index of suspicion for NIHF, the obstetrician or perinatologist should consider further investigations to

Table IV. Chromosomal Abnormalities.

\begin{tabular}{lc}
\hline & Number of cases \\
\hline Down syndrome & 4 \\
Turner syndrome & 4 \\
Translocation & 2 \\
Triploidy & 2 \\
Trisomy 18 & 2 \\
Total & 14 \\
\hline
\end{tabular}


Table V. Etiology of Non-Immune Hydrops Fetalis Based on Gestational Age.

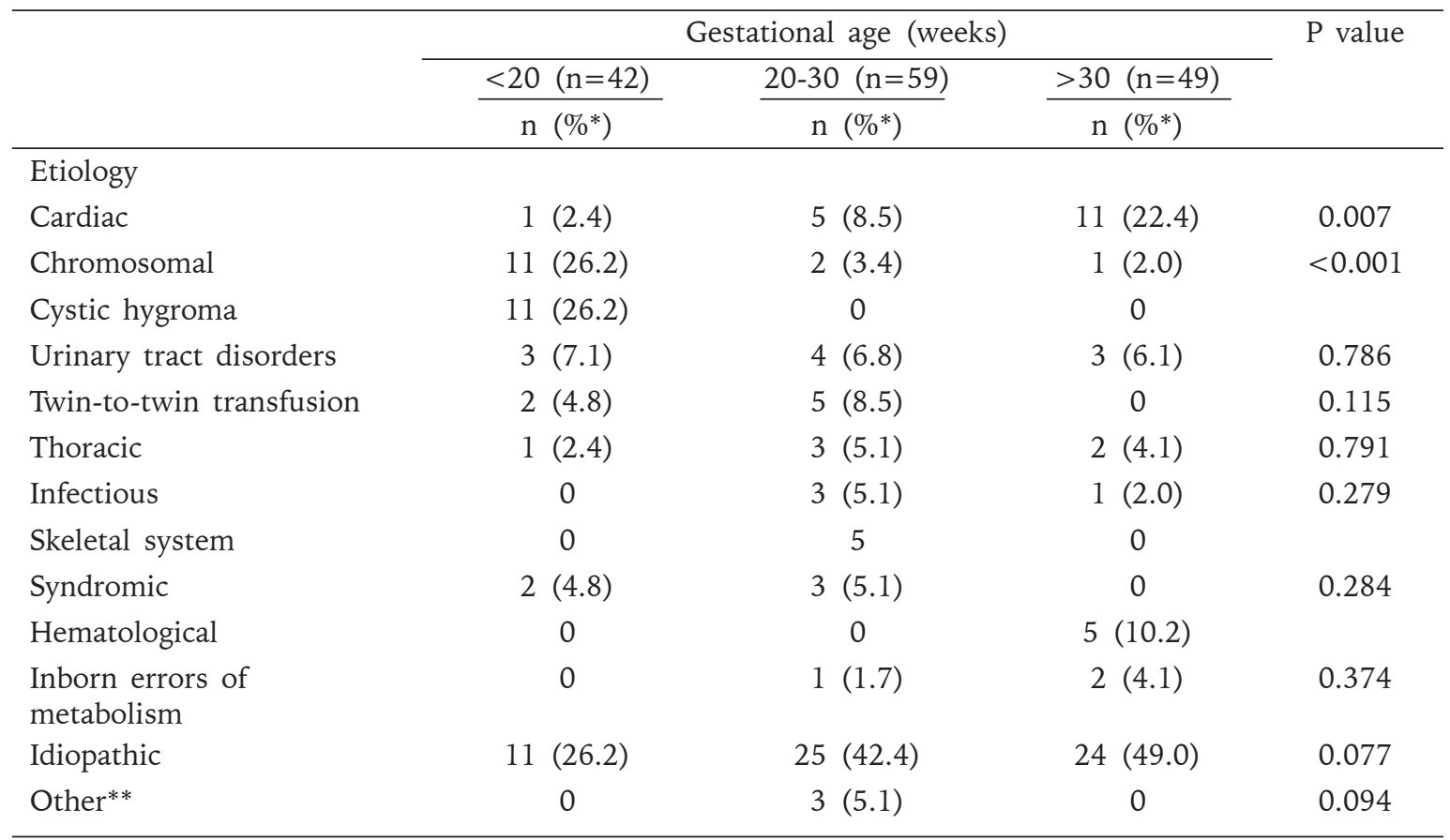

identify potential causes for the disease. Meticulous and comprehensive ultrasonography is necessary to assess fetal morphology in addition to examination of the placenta, amniotic fluid, and vascular structures. ${ }^{5,11}$ Fetal echocardiography must be performed to assess cardiac anatomy and to evaluate for possible heart failure ${ }^{1}$. Doppler examination is an important test in all cases to evaluate fetal wellbeing and to predict fetal anemia 16. Invasive procedures (amniocentesis or cordocentesis) are additional methods to detect fetal chromosomal abnormalities. ${ }^{9,17}$ Moreover, it is important to perform serological examination on maternal blood samples for evaluation of immunoglobulins or infectious agents. ${ }^{10,18}$ Furthermore, hereditary metabolic disorders and obstetrical complications (twinto-twin transfusion and placental masses) should be considered among potential etiologies of NIHF. ${ }^{13,19}$ Improved prenatal interventions secondary to technological advances have helped in better detection rates for this condition. Additionally, underlying etiologies can be identified through an autopsy in some cases.

In a recent study, we reported that overall mortality rate of NIHF cases is $78.2 \%$ (147 in the period 2001-2013) and autopsy results were accepted by the concerned families in $34 \%(50 / 115)$ of cases. ${ }^{13}$ We identified at least one etiological factor of NIHF in $80 \%$ of the fetal autopsies that were performed. In that study, we could additionally show that cardiovascular disorders were the most common $(21.7 \%)$ etiological factor, while chromosomal abnormalities were the second most $(12.8 \%)$ common etiological factor of NIHF. ${ }^{13}$ Another study we performed has reported etiological and prognostic factors in live-born infants with HF at our tertiary intensive neonatal center between 2002 and 2011. ${ }^{19}$ We found that an etiological factor could be identified in $70.5 \%$ of the infants diagnosed with NIHF, and that lymphatic dysplasia and cardiovascular disorders were the most common etiological factors $(23.5 \%$ and $11.7 \%$, respectively). Mortality rate of live-born infants diagnosed with NIHF was found to be $44.1 \%$ while this rate was $12.5 \%$ for lymphatic dysplasia associated with NIHF cases. ${ }^{19}$ Similar results have been reported by various other authors. $3,8,20,21$

In this study, which evaluated the role and significance of a fetal autopsy in NIHF cases, we found that the most common etiological 
factor associated with this condition was cardiovascular disorders (11.3\%) followed by chromosomal abnormalities (9.3\%). Prior to 20 weeks of gestation, genetic anomalies and cystic hygroma were found to be the most commonly associated etiological factors while after 30 weeks of gestation, cardiac causes were identified as the most commonly associated etiological factors. Our case series also demonstrated various associated pathological conditions of NIHF, such as cystic hygroma, urinary system malformations, twin-to-twin transfusion, thoracic anomalies, skeletal dysplasia, infection, various genetic syndromes, fetal anemia, inborn errors of metabolism, central nervous system anomalies, chorioangioma, and maternal Sjögren syndrome. Unfortunately, the etiology-undefined group showed an incidence of $48.4 \%$ and $33.7 \%$ in the 1984-2004 and 2005-2015 periods, respectively. We reckon that a fetal autopsy is very important for the diagnosis, confirmation, and reporting of NIHF cases associated with structural abnormalities. Changes in medical practice secondary to social and technological advancement have facilitated better physicianpatient interaction. This has allowed patients and their families to discuss and obtain a better explanation of pathological conditions in relevant effective cooperation and collaboration between perinatologists, neonatologists, and pathologists is required in this regard.

Metabolic diseases can cause NIHF. This may be due to visceromegaly which can affect venous circulation in storage diseases. Hypersplenism which causes anemia, cardiac involvement and/ or hypoalbuminemia can also be the other reasons of NIHF in metabolic diseases. ${ }^{21}$ There were 3 metabolic diseases related with NIHF (Niemann Pick disease type C in 1, lysosomal storage disease type 7 in 1 and Zellweger disease in 1) in our study which shows the importance of further investigation by fetal autopsy.

A wide spectrum of pathologies may cause impaired fetal hemodynamic status resulting in $\mathrm{HF}$ at different time points during gestation. ${ }^{20}$ Chromosomal abnormalities have been reported to be the most common etiological factor associated with NIHF during the second trimester of pregnancy. ${ }^{22}$ In our study as well, we demonstrated that chromosomal abnormalities were the predominant etiological factor leading to NIHF.

We propose that a fetal autopsy should not be restricted to only a histopathological evaluation but should also include genetic studies. Molecular and genetic studies associated with a fetal autopsy could prove to be a promising approach in the future with respect to management of such cases.

In conclusion, better genetic tests/genomic studies are required to improve the management of prenatally diagnosed NIHF cases.

\section{REFERENCES}

1. Norton ME, Chauhan SP, Dashe JS; Society for MaternalFetal Medicine (SMFM). Society for maternal-fetal medicine (SMFM) clinical guideline\# 7: nonimmune hydrops fetalis. Am J Obstet Gynecol 2015; 212: 127139.

2. Bellini C, Hennekam RC, Fulcheri E, et al. Etiology of nonimmune hydrops fetalis: A systematic review. Am J Med Genet A 2009; 149A: 844-851.

3. Ismail K, Martin W, Ghosh S, Whittle MJ, Kilby MD. Etiology and outcome of hydrops fetalis. J Matern Fetal Neonatal Med 2001; 10: 175-181.

4. Ota S, Sahara J, Mabuchi A, Yamamoto R, Ishii K, Mitsuda N. Perinatal and one-year outcomes of non-immune hydrops fetalis by etiology and age at diagnosis. J Obstet Gynaecol Res 2016; 42: 385-391.

5. Sohan K, Carroll SG, De La Fuente S, Soothill P, Kyle P. Analysis of outcome in hydrops fetalis in relation to gestational age at diagnosis, cause and treatment. Acta Obstet Gynecol Scand 2001; 80: 726-730.

6. Anandakumar C, Biswas A, Wong YC, et al. Management of non-immune hydrops: 8 years' experience. Ultrasound Obstet Gynecol 1996; 8: 196-200.

7. Carlson DE, Platt LD, Medearis AL, Horenstein J. Prognostic indicators of the resolution of nonimmune hydrops fetalis and survival of the fetus. Am J Obstet Gynecol 1990; 163(6 Pt 1): 1785-1787.

8. Rodríguez MM, Chaves F, Romaguera RL, Ferrer PL, De la Guardia C, Bruce JH. Value of autopsy in nonimmune hydrops fetalis: Series of 51 stillborn fetuses. Pediatr Dev Pathol 2002; 5: 365-374.

9. Santolaya J, Alley D, Jaffe R, Warsof SL. Antenatal classification of hydrops fetalis. Obstet Gynecol 1992; 79: 256-259.

10. Beksac MS, Saygan-Karamürsel B, Ustacelebi Ş, et al. Prenatal diagnosis of intrauterine cytomegalovirus infection in a fetus with non-immune hydrops fetalis. Acta Obstet Gynecol Scand 2001; 80: 762-765.

11. van Kamp IL, Klumper FJ, Bakkum RS, et al. The severity of immune fetal hydrops is predictive of fetal outcome after intrauterine treatment. Am J Obstet Gynecol 2001; 185: 668-673. 
12. Parilla BV, Strasburger JF, Socol ML. Fetal supraventricular tachycardia complicated by hydrops fetalis: A role for direct fetal intramuscular therapy. Am J Perinatol 1996; 13: $483-486$.

13. Turgal M, Ozyuncu O, Boyraz G, Yazicioglu A, Beksac MS. Non-immune hydrops fetalis as a diagnostic and survival problems: What do we tell the parents? J Perinat Med 2015; 43: 353-358.

14. Bellini C, Hennekam RC. Non-immune hydrops fetalis: A short review of etiology and pathophysiology. Am J Med Genet A 2012; 158A: 597-605.

15. Liao C, Wei J, Li Q, Li J, Li L, Li D. Nonimmune hydrops fetalis diagnosed during the second half of pregnancy in Southern China. Fetal Diagn Ther 2007; 22: 302-305.

16. Désilets V, Audibert F; Society of Obstetrician and Gynaecologists of Canada. Investigation and management of non-immune fetal hydrops. J Obstet Gynaecol Can 2013; 35: 923-938.
17. Beksac MS, Ozlu T, Dikensoy E, Cebesoy B. Management of severe non immune hydrops fetalis cases: The role of diagnostic and/or therapeutic interventions. Gynecol Obstet Reprod Med 2009; 15: 85-88.

18. Bellini C, Donarini G, Paladini D, et al. Etiology of non-immune hydrops fetalis: An update. Am J Med Genet A 2015; 167A: 1082-1088.

19. Takci S, Gharibzadeh M, Yurdakok M, et al. Etiology and outcome of hydrops fetalis: Report of 62 cases. Pediatr Neonatol 2014; 55: 108-113.

20. Parks WT. A pathologist's approach to nonimmune hydrops. J Fetal Med 2015; 2: 143-149.

21. Fukushima K, Morokuma S, Fujita Y, et al. Short-term and long-term outcomes of 214 cases of non-immune hydrops fetalis. Early Hum Dev 2011; 87: 571-575.

22. Heinonen S, Ryynänen M, Kirkinen P. Etiology and outcome of second trimester non-immunologic fetal hydrops. Acta Obstet Gynecol Scand 2000; 79: 15-18. 